\title{
Pulse or hyaline ring granuloma. Review of the literature on etiopathogenesis of oral and extraoral lesions
}

\author{
Hans Peter Philipsen • Peter A. Reichart
}

Received: 3 May 2009 / Accepted: 21 July 2009 /Published online: 29 August 2009

(C) Springer-Verlag 2009

\begin{abstract}
Since the late 1950s, reports on an unusual giantcell granulomatous lesion affecting the jaws, lungs, stomach and intestines have been published. Histopathologically, the lesions showed the presence of structureless hyaline rings with multinucleated giant cells. The aim of this review was to summarize the literature on the etiopathogenesis of the socalled oral and extraoral pulse or hyaline ring granuloma. Literature was searched using PubMed and Medline. In addition, hand search was performed. Search words were oral and extraoral hyaline ring granuloma, giant-cell hyaline angiopathy, pulse granuloma and chronic periostitis. Numerous terms for hyaline ring granuloma have been introduced over time (1971-2008). One hundred seventy-three cases of oral hyaline ring granuloma have been retrieved from the literature. In the mandible, $72.3 \%$ occurred . Two theories for etiopathogenesis have been proposed: (1) the origin of the hyaline rings is due to a foreign material (pulse and legumes) having penetrated the oral mucosa or gastrointestinal tract and lungs (exogenous theory) and (2) the rings are due to hyaline degenerative changes in walls of blood vessels (endogenous theory). Experimental production of oral and extraoral hyaline ring granulomas is consistent with the exogenous origin. Particles or remains of leguminous cells having been implanted or aspirated into human tissues whether located to the oral cavity or throughout the entire
\end{abstract}

H. P. Philipsen

Vejlesoeparken,

2840 Holte, Denmark

P. A. Reichart $(\bowtie)$

Department of Oral Surgery and Stomatology, University of Bern,

Freiburgstrasse 7 ,

3010 Bern, Switzerland

e-mail: peter.reichart@zmk.unibe.ch

e-mail: peter-a.reichart@charite.de digestive tract and respiratory system are thought to be causative. Pulse or hyaline ring granulomas are rare but are well-defined oral and extraoral lesions due to implantation of the cellulose moiety of plant foods in contrast to the starch components.

Keywords Chronic periostitis · Giant cell hyaline angiopathy . Oral and extraoral pulse or hyaline ring granuloma Oral vegetable granuloma

\section{Introduction}

Over the years, in fact, since 1971 [1], there have been several reports of an unusual oral giant-cell granulomatous lesion affecting either jaws or the posterior mandibular alveolar ridge in particular. The lesion was initially described as "chronic periostitis" characterized by the presence of rings of palely eosinophilic structureless material-so-called hyaline rings (HR) - with numerous multinucleated giant cells around and within the rings and in common with other granulomas showing areas of fibrosis with mature fibroblasts, vacuolated macrophages, plasma cells and lymphocytes. The term "HR" was coined by Dunlap and Barker [2] who were of the opinion that these structures were of endogenous origin (hyaline degenerative changes in the walls of blood vessels). This is in contrast to the view expressed by Lewars [1] and several later authors who considered that minute food particles were impounded on the mucous membrane and driven into the submucous tissue of the periosteum, where they provoke a foreign body reaction. Some authors, Rannie [3], Yang and Barnett [4], and Keirby and Soames [5] suggested an alternative name-hyaline bodies (HB) - for the above structures, a term that has proved to cause some terminology confusion, and the present 
authors shall return to this problem at a later stage. Adkins [6] thought it likely that the foreign food particles have been accidentally or intentionally introduced into sockets following dental extractions. The HRs were later (King [7]) identified as structures originating from fragments of pulses (edible seeds of legumes), and the above lesion is hereafter termed oral pulse or hyaline ring granuloma (OPHRG). It should, however, be noticed that although the vast majority of these lesions have been reported as occurring intraorally, several reports - some even published years ahead of oral lesions - have dealt with extraoral, in particular, pulmonary lesions.

This article presents a critical review of the literature on the etiopathogenesis of the previously mentioned OPHRG and/or extraoral pulse or HR granuloma (EOPHRG).

\section{Terminology}

A review of the literature on OPHRG discloses a wide variety of terms describing this lesion [1-31], e.g. chronic mandibular periostitis [1-3], giant-cell hyaline angiopathy $[2,16,18], \mathrm{HB}$ and giant cells associated with a radicular cyst [4], periostitis and osteitis associated with HB [5], granulomas in edentulous jaws [6], pulse granuloma [7, 10, $12,14,15,19,21,22,24,26,28,30]$, oral vegetable granuloma [17], HR granuloma [13, 23, 27, 29, 31], le granulome "alimentaire" des maxillares [25], food-induced granuloma [20]and granuloma tissue with giant cells and hyaline change [12]. The report by Hase et al. [9] obviously represents a case of oral infection due to Torulopsis glabrata but superimposed on a case of OPHRG.

\section{Etiopathogenetic theories (OPHRG)}

As alluded previously, two opposing etiological theories have been advanced concerning the origin of the HRs, and thus, the pathogenesis of the granulomatous lesion. The first is that these structures are derived from a foreign material (exogenous theory), most likely, legumes (pulse) or vegetable material, hence the previous term OPHRG. The second (endogenous) theory proposes that the rings, according to Dunlap and Barker [2], represent a hyaline degenerative change in the walls of blood vessels, leading to the diagnostic term giant-cell hyaline angiopathy.

\section{Exogenous theory}

Lewars[1] initially suggested that "minute food particles are impounded on the mucous membrane and driven into the submucous tissue of the periosteum, where they provoke a foreign body reaction". Adkins [6] who first drew attention to "rings of palely stained eosinophilic structureless material," diagnosed the histological features as those of foreign-body granulomas. He suggested that among several possible exogenous materials, food debris may incidentally have been inserted into sockets following tooth extractions. Rannie [3] found that legume parenchymatous cells in various stages of breakdown, as a result of disruption by cooking and attempted degradation by host phagocytic cells, were producing the ring-like structures seen in the oral lesions. In an attempt to further identify the foreign material, he made a histological preparation of the contents of a tin of lentil soup which appeared to be an almost pure suspension of legume parenchymatous cells filled with starch. Over the years, 19 reports $[1,3,5-7,10,14,15,17$, 20-22, 24-28, 31] have supported the viewpoint that exogenous foreign material, especially from leguminous food (pulse), is responsible for the formation of HRs and causing the development of OPHRGs.

\section{Endogenous theory}

This theory was initially introduced by Dunlap and Barker [2] who believed that the characteristic HRs represent a degenerative change in the walls of vessels precipitated by a localized acute vasculitis, hence their suggested term giant-cell hyaline angiopathy. The same authors, 10 years later (Barker and Dunlap [18]), felt—based on more recent literature, and in particular, the detailed report by Harrison and Martin [16] - that the intervening years had not produced convincing evidence to support legumes or other vegetable matter as the sole cause of the HRs.

\section{"Various theories"}

As touched upon previously, a few authors (Yang et al. [4] and Chen et al. [11]) have caused some terminology confusion by mixing up the term HRs with HBs. The last mentioned structures (HBs), often referred to as Rushton bodies, and well known to oral pathologists albeit in another context (Shear [32]), are morphological as well as etiologically quite different from HRs. HBs can be found in about $10 \%$ of various odontogenic cysts, notably in the epithelial lining. They are eosinophilic and measure up to about $0.1 \mathrm{~mm}$ and are linear, straight or curved or of hairpin shape. They are of odontogenic epithelial origin and of much debated composition (Shear [32]). However, all evidence points at $\mathrm{HBs}$ being of endogenous origin.

Oral pulse or hyaline ring granuloma: epidemiological data

Table 1 summarizes 26 publications where clinical epidemiological data were registered covering a total of 173 patients with OPHRGs. The ages ranged from 6 to 71 years 
Table 1 Oral pulse or hyaline ring granuloma (clinical cases) according to number of cases, age, gender and location

\begin{tabular}{|c|c|c|c|c|c|c|}
\hline \multirow[t]{2}{*}{ Author } & \multirow[t]{2}{*}{ No. of cases } & \multirow[t]{2}{*}{ Age (years); median (range) } & \multicolumn{2}{|l|}{ Gender } & \multicolumn{2}{|l|}{ Location } \\
\hline & & & Males & Females & Maxilla & Mandible \\
\hline Lewars [1] & 6 & $38.5(29-42)$ & 4 & 2 & 0 & 6 \\
\hline Adkins [6] & 15 & n.i. $(37-51)$ & 9 & 6 & 2 & 13 \\
\hline Rannie [3] & 16 & n.i. & n.i & n.i. & 4 & 12 \\
\hline Hase et al. [9] & 1 & 51 & 1 & & & 1 \\
\hline Dunlap and Barker [2] & 7 & n.i. $(6-71)$ & 4 & 3 & 1 & 6 \\
\hline Mincer et al. [10] & 6 & n.i. (19-69) & 6 & & 1 & 5 \\
\hline McMillan et al. [12] & 5 & $48.2(30-68)$ & 4 & 2 & & 6 \\
\hline Chen et al. [11] & 2 & 20 and 59 & 2 & & 1 & 1 \\
\hline Ide et al. [15] & 1 & 21 & & 1 & & 1 \\
\hline Simon et al. [14] & 1 & 58 & 1 & & 1 & \\
\hline Ciola et al. [16] & 1 & 67 & 1 & & 1 & \\
\hline Yang and Barnett [4] & 1 & 67 & & 1 & & 1 \\
\hline Keirby and Soames [5] & 17 & $56(39-71)$ & 14 & 3 & 1 & 16 \\
\hline Idem $[5]$ & 7 & n.i. & n.i. & n.i. & n.i. & n.i. \\
\hline Harrison and Martin [17] & 4 & $63(60-65)$ & 2 & 2 & & 4 \\
\hline Idem [17] & 6 & $29.5(20-63)$ & 3 & 3 & 4 & 2 \\
\hline Ferguson and Smile[18] & 1 & 37 & 1 & & & 1 \\
\hline Brown and Theaker [20] & 1 & 65 & & 1 & & 1 \\
\hline Talacko and Radden [22] & 62 & n.i. $(13-68)$ & 37 & 25 & 25 & 36 \\
\hline Chou et al. [23] & 2 & $60.5(55-66)$ & 2 & & & 2 \\
\hline Iiarte Ortabe et al. [25] & 1 & 41 & & 1 & & 1 \\
\hline Marcussen et al. [26] & 3 & $40.3(30-57)$ & 2 & 1 & 2 & 1 \\
\hline Lin et al. [27] & 1 & 20 & 1 & & 1 & \\
\hline LaMear et al.[28] & 1 & 64 & 1 & & & 1 \\
\hline Keskin et al.[29] & 2 & 18 and 38 & & 2 & 1 & 1 \\
\hline Pola et al.[30] & 1 & 16 & 1 & & 1 & \\
\hline Sato et al.[31] & 1 & 28 & 1 & & & 1 \\
\hline \multirow[t]{3}{*}{ Philipsen amd Reichart ${ }^{\mathrm{a}}$} & 1 & 16 & 1 & & 1 & \\
\hline & 173 & & 97 & 53 & 46 & 120 \\
\hline & & & $64.7 \%$ & $35.5 \%$ & $27.7 \%$ & $72.3 \%$ \\
\hline
\end{tabular}

n.i. no information

${ }^{a}$ Vide paragraph on case report

with the majority belonging to the adult age group of which almost two thirds were males. More than two thirds of the lesions occurred in the lower jaw commonly in the premolar-molar region in an edentulous patient with a full lower denture or in the walls of residual/periapical cysts, in granulomas involving carious teeth/tooth roots left open or teeth with a history of failed/incomplete endodontic therapy. Most patients presented with signs or symptoms of pain, swelling, discharge or a chronic sinus, or the lesions were initially found on routine clinical and radiological examination. Treatment was by excision or curettage.

\section{Portal of entry of vegetable matter in EOPHRGs}

Whereas, the vast majority of pulse or HR granulomas have been reported as occurring in the oral region, some reports have dealt with extraoral, in particular, pulmonary lesions in infants or severely debilitated persons caused by aspirated fragments of pulses [33-40]. Knoblich [37] found 41 cases of pulse granuloma in lung tissue (pulmonary nodular granulomatosis, lentil pulse pneumonia or vegetable aspiration pneumonia) from approximately 1,500 autopsies. The author also did some animal experiments (see succeeding paragraph on this subject). The author 
concluded that the granuloma-inducing substance was the cellulose component of the lentil particles and not the starch.

The granulomatous condition has also been reported in the walls of stomachs resected from peptic ulcer patients [41] and diffusely scattered through the peritoneal cavity. Martin et al. [42] published an unusual case of "cutaneous giant-cell hyaline angiopathy" where the patient, after a hip replacement, developed a lesion of the left buttock that was not associated with the surgical scar.

Zhai and Maluf [43] and Stewart and Hillary [44] reported cases of peridiverticular colonic HR or pulse granulomas associated with perforated diverticulitis. Pereira et al. [45] presented the first case of a rectal pulse granuloma, and Tschen and Tschen [46] reported a tumour in the patient's left buttock. A colonoscopy showed a fistula opening in the rectal wall, and histology revealed granulomatous inflammation and multiple HRs.

Rhee and $\mathrm{Wu}$ [47] demonstrated that pulse granulomas can occur outside the digestive tract and lungs in association with passage of gastrointestinal contents through fistulae. The cases involved the gallbladder, fallopian tube and skin, respectively. Lastly, Nambudripad et al. [48] recently reported a highly unusual pulse granuloma that occupied periprostatic soft tissue and that was iatrogenically caused by prostatic core biopsies.

EOPHRGs are important lesions for the following reasons: (1) large lesions, which may reach to $2.5 \mathrm{~cm}$ in diameter can masquerade as neoplasia, (2) the granulomas may be easily misdiagnosed as hyaline vasculopathy of hypertension, diabetes or amyloidosis due to the fact that many pathologists are far more aware of these entities than they are of the granulomas mentioned here, and (3) EOPHRGs can be surrogate markers of serious pathology that enables vegetable matter to escape the gastrointestinal tract. Thus, the presence of these lesions should always prompt consideration of gastrointestinal fistulae, diverticula, or perforation, which may be histologically apparent but clinical occult.

\section{Experimental production of OPHRGs}

Talacko and Radden [21] developed an animal experimental model to determine whether implanted food particles of plant origin were responsible for the development of these lesions. Homogenized cooked lentils were introduced into the oral submucosa and cavities prepared in the lower border of the mandible in male SpragueDawley rats. Typical HRs enclosing chronic inflammatory cells, connective tissue or multinucleate cells were noted as early as the third day. They appear as eosinophilic or faintly basophilic rounded structures of homogenous or fibrillar nature. Apparently, the starch grains were very rapidly digested.

Talacko and Radden's animal model provided the medium to observe the chronological development of oral pulse granuloma and showed that the human and the experimental lesions exhibit a few histological differences. The grossly thickened collagen rings observed in human sections were not noted in the animal material. According to Harrison and Martin [17], the deposition of collagen at the surface of the HR may take longer than the 6 months which was the maximum observation time in the animal group.

Other investigators [5, 37] have suggested that lectin, phytates and lathyrogens, all of which are known to disturb collagen metabolism and cause agglutination of erythrocytes and leucocytes, are responsible for the specific granulomatous response caused by legumes. However, even ordinary food preparation methods such as cooking or canning are likewise able to destroy these substances. The most recent experimental study using an animal model was reported by Watson and Stewart [24] who examined the histological appearance of various vegetable foreign material and the host responses to them. Incisions were made on the dorsal skin of a Sprague-Dawley rat with subcutaneous implantation of the following minced vegetable substances: lentils, peas, beans, rice, apples, corn, celery, potato chips, lettuce and chewing tobacco. The authors stated that histologically implanted lentils, peas and navy beans showed the characteristic features of pulse granulomas encountered in human beings. The remaining vegetable substances failed to show the large, compartmentalized ovoid structures seen with pulses.

\section{Experimental production of EOPHRG}

In order to define chronological the sequence of the pneumonic process that takes place in humans after aspiration of leguminous particles, Knoblich [37] performed a series of animal experiments. Broth of cooked peas, beans and lentils was injected intratracheally and also directly into the lungs of guinea pigs, cats and rabbits, and he was able to reproduce the equivalent of the pulmonary lesions in humans. The author concluded that the granuloma-inducing substance was the cellulose component and not the starch. The cellulose of other vegetables such as carrots and onions is not capable of producing extensive long-lasting granulomatous lesions. The possibility that the granulomatous lesions represented allergic granulomas was considered by the author because leguminous seeds contain, besides starch, an appreciable amount of protein material and, in addition, legumes are rich in phytohaemagglutinins, which have been shown to possess granulomaenhancing properties [37]. 


\section{Case report}

In order to document a characteristic case of OPHRG, the following clinical data and histological features of the curetted material are presented.

A 16-year-old male patient presented himself to the local dentist (R.W.) because of pain in the area of the left maxillary second premolar. The crown of the tooth had been restored earlier with a large composite filling. A vitality test was performed with an ambigious response. Periapical radiograph did not reveal periapical pathology. The root canal was opened and irrigated with sodiumchloride and EDTA. The root canal was filled with calciumhydroxide and a temporary filling was applied. The patient was unreliable, and he returned only after 6 months when the temporary filling was missing. The root canal was irrigated again, and 1 day following this treatment, the patient returned with local pain. Irrigation was repeated, and the canal was left open. Two days later, the patient returned for the second time with pain and a radiograph (Fig. 1) showed now a widening of the periodontal ligament in the apical region. The tooth was left open and the patient referred for apicoectomy, which was performed 7 days later. The curetted periapical material was submitted for microscopy. Wound healing was optimal, and no further treatment was needed. The histopathological features revealed rings of pale-staining, eosinophilic material, multinucleated giant cells within and around the rings and a stroma infiltrated by non-specific chronic inflammatory cells (Figs. 2, 3). The diagnosis of oral pulse

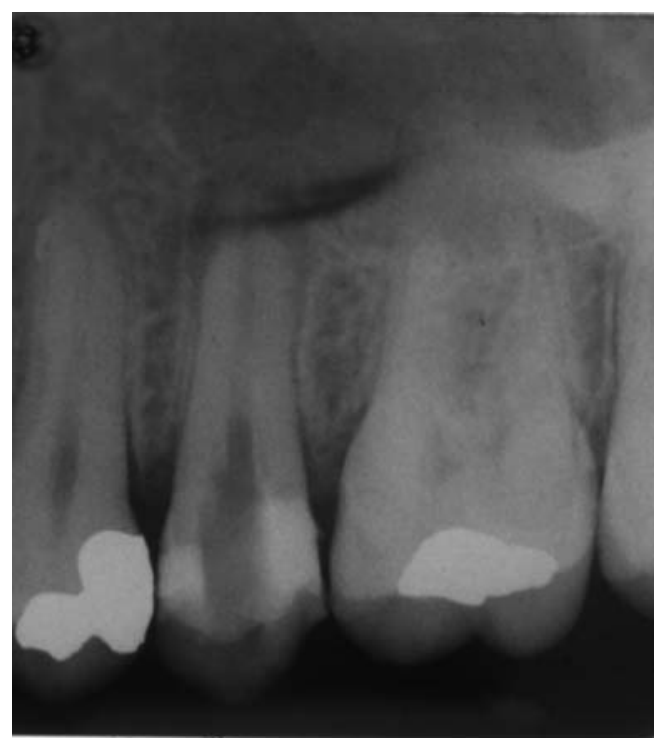

Fig. 1 Periapical radiograph. The left second maxillary premolar shows a widened periodontal ligament at the periapex of the tooth. The floor of the maxillary sinus appears to be eroded apical to the apex of the root of tooth 25 . A horizontal, radiolucent artefact is seen overlying the apical region of the tooth

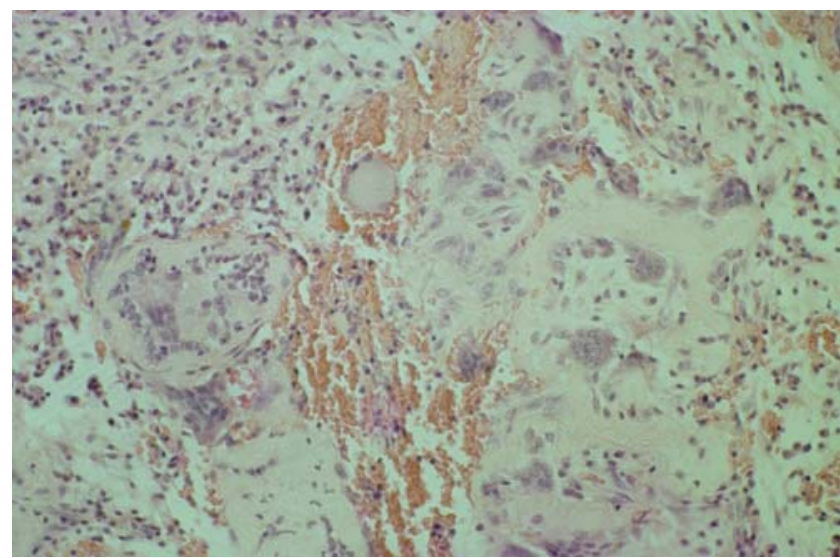

Fig. 2 Hyaline ring granuloma. Granulomatous tissue with infiltration of immunocompetent cells and distinct hyaline ring formations $(\mathrm{H} \&$ $\mathrm{E}, \times 80)$

granuloma was made. The portal of entry of the food particles was, in this case, quite obviously the root canal of the premolar left open during the endodontic treatment.

\section{Are certain food habits associated with or provoking the development of pulse or HR granuloma in patients with a "British Lifestyle"?}

In order to address the above rather intriguing question, Table 2 enumerates patients with accepted cases of OPHRG according to their home countries (as recording in the respective publications). The vast majority ( $96 \%$ ) of the cases have been reported as occurring in patients in countries that may be categorized as following mainly a "British Lifestyle" (UK, Australia, USA, New Zealand and Canada). These patients may well be indulging in "British food habits" and favouring a certain amount of leguminous food products.

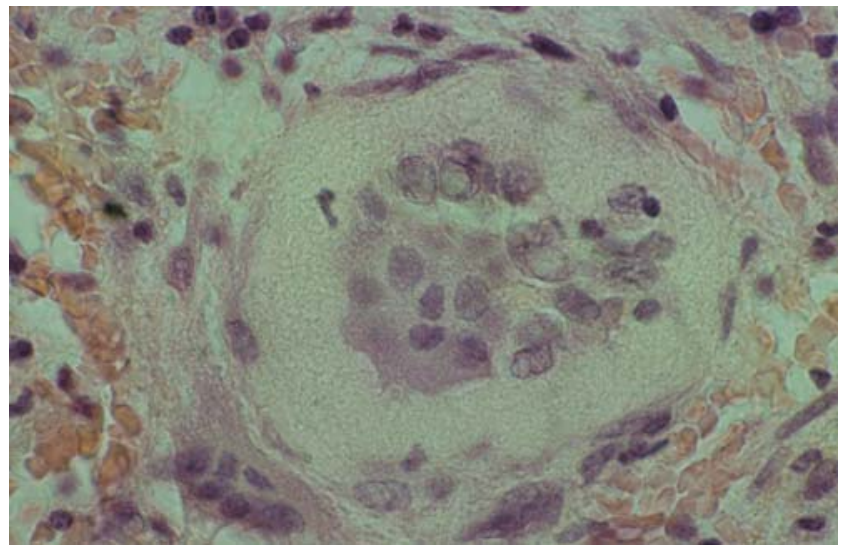

Fig. 3 Higher magnification of an area with characteristic hyaline ring formation $(\mathrm{H} \& \mathrm{E}, \times 140)$ 
Table 2 Number of OPHRG-patients according to home country

\begin{tabular}{ll}
\hline Country & No. of patients \\
\hline UK [1, 3, 5, 13, 17, 20] & 74 \\
Australia [9, 22] & 63 \\
USA [2, 4, 8, 10, 11, 14, 16, 23, 28] & 23 \\
New Zealand [6, 12, 18] & 21 \\
Canada [26] & 3 \\
Japan [15, 31] & 2 \\
Turkey [29] & 2 \\
Belgium [25] & 1 \\
Taipei [27] & 1 \\
Spain [30] & 1 \\
Germany $^{\mathrm{a}}$ & 1 \\
\hline
\end{tabular}

${ }^{\text {a }}$ Vide paragraph on case report

Grain legumes are plants belonging to the Leguminosae order and are cultivated throughout the world, primarily for their grains. Pulses are the edible seeds of leguminous plants such as peas, beans, lentils etc. According to Schneider [49], the annual consumption of pulses per individual in 1999 (kg/capita per year) were as follows: North and Central America, 7.2; EU-15 (at the time covering 15 member states), 3.9; UK, 6.6 and Australia, 9.1. Leterme [50], in his report on recommendations by health organizations for pulse consumption, concludes that pulses are seen as a staple food because they are nutritious and provide most of the ingredients that help to improve health (complex carbohydrates, minerals etc.). This could encourage more consumers who are concerned about their health to consider consuming pulses more frequently. If the above theorized relationship, British lifestyle/food habits and the risk of development of OPHRG should prove correct, it could tend to increase the number of patients with this quite unique granulomatous lesion.

\section{Discussion}

A thorough review of the relevant literature disclosed that the lesion in question according to all available evidence is triggered by particles or remnants of leguminous cells having been implanted or aspirated into human tissues whether located to the oral cavity or through the entire digestive tract and respiratory system. The cellulose moiety of plant foods is, in contrast to the starch component indigestible and persists in the human tissues in the form of hyaline (eosinophilic) material, inciting a chronic granulomatous response. It has been shown that collagen is laid down at the periphery of the cellulose components with time, thus explaining the difference between the thick HRs and the thin plant cell walls.

Even though a portal of entry may not always be evident, Levison et al. [49] disclosed the presence of an unexpectedly wide range of foreign elements in routine biopsies, indicating that implantation can occur without gross trauma to the tissues. Oral pulse granuloma is most commonly found in the mandible, particularly in the posterior regions where food stagnation is common. It is conceivable that food particles are lodged under an atrophic mucosa overlying the alveolar ridge of mainly elderly individuals and are maintained there by the pressure of a denture. Gross dental caries or a root canal, which is left open to the oral cavity are patent pathways for entry of food particles into the periapical tissues. Pericoronitis around the lower third molar teeth with stagnation in the area also provides a pathway for food to be lodged submucosally as doe's part of a dentigerous cyst wall present in the area. The possibility of foodstuffs entering extraction sites and surgical incisions is obvious portals of entry.

The findings presented in our review do not lend support to the endogenous theory initially advanced by Dunlap and Barker [2, 19]. In the light of the pathogenesis, it is surprising that oral pulse granuloma is not more commonly reported. However, if only small portions of food particles gain access to the tissues, the ensuing response may well be subclinical. The correct diagnosis which requires microscopy of the removed pathological tissue includes: a chronic inflammatory lesion characterized by the presence of foreign-body giant cells associated with eosinophilic HRs often appearing as roughly circular homogenous or fibrillar masses which may exhibit a corrugated border lying within a chronically and, less often, acutely inflamed fibrous tissue stroma. Small, spherical foci of calcification may be found in the lumina of the HRs or, the entire mass may be calcified.

Based on the regular use of leguminous foods (pulses) in the human diet, it is surprising that intake of legumes is extremely rare, if ever reported to be associated with the development of a pulse granuloma, apart from the occurrence of vegetable aspiration or lentil pulse pneumonia in debilitated patients and children. In fact, among the 32 reports reviewed here on OPHRG, only one author (LaMear et al. [28]) discloses the direct association of legume-intake with oral pulse granuloma. A 64-year-old Missouri farmer complained of a mass adjacent to the margin of his right mandible. The microscopical diagnosis of oral pulse granuloma was made. The author terminated his report as follows: "Our patient was an edentulous farmer who had a habit of walking his fields chewing 
freshly gathered beans, as well as having a diet rich in lentil soup. He has been cautioned as to the hazards of this activity."

Acknowledgement We are grateful to Dr. R. Wolf and Dr. U. Bosse, Osnabrück, Germany, for allowing us to publish the present case. We would also like to thank Prof. Dr. H. Ostertag, Pathologisches Institut Klinikum Hannover im Krankenhaus Nordstadt, Hannover, Germany, who kindly placed microscopical slides from the previously discussed case report at our disposal.

Conflict of interest The authors declare that they have no conflict of interest.

\section{References}

1. Lewars PHD (1971) Chronic periostitis in the mandible underneath artificial dentures. Br J Oral Surg 8:264-269

2. Dunlap CL, Barker BF (1977) Giant-cell hyalin angiopathy. Oral Surg Oral Med Oral Pathol 44:587-591

3. Rannie I (1975) Chronic mandibular periostitis associated with "vasculitis". Pathol Microbiol 43:115-119

4. Yang Z-P, Barnett F (1985) Hyaline bodies and giant cells associated with a radicular cyst. Endod Dent Traumatol 1:85-87

5. Keirby FAR, Soames JV (1985) Periostitis and osteitis associated with hyaline bodies. Br J Oral Maxillofac Surg 23:346-350

6. Adkins KF (1972) Granulomas in edentulous jaws. N Z Dent J 68:209-212

7. King OH Jr (1978) "Giant cell hyaline angiopathy": pulse granuloma by another name? Presented at the 32nd Annual Meeting of the American Academy of Oral Pathology, Fort Lauderdale, Florida, 23-29 April 1978

8. Cataldo E, Santis H (1974) Response of the oral tissue to exogenous foreign materials. J Periodontol 45:93-106

9. Hase MP, Radden BG, Reade PC (1976) Torulopsis glabrata infection in the oral cavity. J Oral Pathol 5:8-16

10. Mincer HH, McCoy JM, Turner JE (1979) Pulse granuloma of the alveolar ridge. Oral Surg Oral Med Oral Pathol 48:126130

11. Chen S-Y, Fantasia JE, Miller AS (1981) Hyaline bodies in the connective tissue wall of odontogenic cysts. J Oral Pathol 10:147157

12. McMillan MD, Kardos TB, Edwards JL et al (1981) Giant cell hyaline angiopathy or pulse granuloma. Oral Surg Oral Med Oral Pathol 52:178-186

13. El-Labban NG, Kramer IRH (1981) The nature of the hyaline rings in chronic periostitis and other conditions: an ultrastructural study. Oral Surg Oral Med Oral Pathol 51:509-515

14. Simon JHS, Chimenti RA, Mintz GA (1982) Clinical significance of the pulse granuloma. J Endod 8:116-119

15. Ide F, Kusama K, Saito I, Umemura S (1982) Pulse granuloma in the wall of a dentigerous cyst. J Oral Maxillofac Surg 40:659-662

16. Ciola B, Bahn SL, Yesner R (1983) Radiographic changes associated with giant cell hyaline angiopathy. Oral Surg Oral Med Oral Pathol 55:108-112

17. Harrison JD, Martin IC (1986) Oral vegetable granuloma: ultrastructural and histological study. J Oral Pathol 15:322326

18. Ferguson JW, Smillie AC (1986) Giant cell hyaline angiopathy presenting as a facial sinus in a patient with undiagnosed diabetes mellitus. N Z Dent J 82:149-151
19. Barker BF, Dunlap CL (1987) Hyaline rings of the oral cavity: the so-called "pulse" granuloma redefined. Semin Diagn Pathol 4:237-242

20. Brown AMS, Theaker JM (1987) Food induced granuloma-an unusual cause of a submandibular mass with observations on the pathogenesis of hyaline bodies. Br J Oral Maxillofac Surg $25: 433-436$

21. Talacko AA, Radden BG (1988) The pathogenesis of oral pulse granuloma: an animal model. J Oral Pathol 17:99-105

22. Talacko AA, Radden BG (1988) Oral pulse granuloma: clinical and histopathological features. A review of 62 cases. Int J Oral Maxillofac Surg 17:343-346

23. Chou L, Ficarra G, Hansen LS (1990) Hyaline ring granuloma: a distinct oral entity. Oral Surg Oral Med Oral Pathol 70:318-324

24. Watson RE, Stewart C (1991) Experimental oral foreign body reactions: vegetable materials. Oral Surg Oral Med Oral Pathol $71: 312-316$

25. Iiartre Ortabe JI, Laka A, Marbaix E, Reychler H (1991) Le granulome "alimentaire" des maxillaires. Présentation d'un nouveau cas et revue de la littérature. Actual Odonto-Stomatol 45:25-31

26. Marcussen LN, Peters E, Carmel D et al (1993) Legumeassociated residual cyst. J Oral Pathol Med 22:141-144

27. Lin S-K, Chiang C-P, Ou S-H et al (1993) Hyaline ring granuloma: a case report with histochemical and polarized microscopic studies. J Formos Med Assoc 92:1001-1003

28. LaMear WR, Estrem SA, Spollen LE (1994) Pulse granuloma presenting as a facial mass. Otolaryngol Head Neck Surg 111:522-523

29. Keskin A, Duran S, Alkan A, Günhan Ö (2000) Hyaline ring granuloma in inflammatory odontogenic cysts: report of two cases. J Oral Maxillofac Surg 58:115-118

30. Pola JG, De La Cruz A, Bustillo F et al (2003) Pulse granuloma in the wall of an inflammatory radicular cyst. Otolaryngol Head Neck Surg 129:441-442

31. Sato H, Miyate H, Fukuta Y, Sato M (2005) Hyaline ring granuloma of the mandibular periosteum. Oral Sci Int 2:17-20

32. Shear M (1992) Cysts of the Oral Region, 3rd edn. Wright, Oxford

33. Head MA (1956) Foreign body reaction to inhalation of lentil soup: giant cell pneumonia. J Clin Pathol 9:295-299

34. Emery JL (1960) Two cases of lentil pneumonitis. Proc Roy Soc Med 53:952-957

35. Crome L, Valentine JD (1962) Pulmonary nodular granulomatosis caused by inhaled vegetable particles. J Clin Pathol 15:2127

36. Vidyardhi SC (1967) Diffuse miliary granulomatosis of the lungs due to aspirated vegetable cells. Arch Pathol 83:215-220

37. Knoblich R (1969) Pulmonary granulomatosis caused by vegetable particles. So-called lentil pulse pneumonia. Am Rev Respir Dis 99:380-389

38. Gill DG (1974) Lentil pulmonary granulomatosis. Med J Aust $1: 836-838$

39. Thompson JR (1962) Identification of foreign material in the lungs. Am Rev Respir Dis 85:281-290

40. Maron EM, McAdams HP, Sporn TA et al (1998) Lentil aspiration pneumonia: radiographic and $\mathrm{CT}$ findings. J Comput Assist Tomogr 22:598-600

41. Sherman FE, Moran TJ (1954) Granulomas of stomach. I. Response to injury of muscle and fibrous tissue of wall of human stomach. Am J Clin Pathol 24:415-421

42. Martin RW, Lumadue JA, Corio RL et al (1993) Cutaneous giant cell hyaline angiopathy. J Cutan Pathol 20:356-358

43. Zhai J, Maluf HM (2004) Peridiverticular colonic hyaline rings (pulse granulomas): report of two cases associated with perforated diverticula. Ann Diagn Pathol 8:375-379 
44. Stewart CJR, Hillery S (2005) Peridiverticular colonic hyaline rings (pulse granulomas). Ann Diagn Pathol 9:305-306

45. Pereira TC, Prichard JW, Khalid M et al (2001) Rectal pulse granuloma. Arch Pathol Lab Med 125:822-823

46. Tschen JA, Tschen JA (2008) Pulse granuloma in a rectocutaneous fistula. J Cutan Pathol 35:343-345

47. Rhee DD, Wu ML (2006) Pulse granulomas detected in gallbladder, fallopian tube, and skin. Arch Pathol Lab Med 130:1839-1842
48. Nambudripad R, Narula N, Wu ML (2008) Iatrogenic pulse granuloma detected at prostatectomy. Int J Surg Pathol 16:96100

49. Schneider AVC (2002) Overview of the market and consumption of pulses in Europe. Br J Nutrit 88(Suppl 3):S243$\mathrm{S} 250$

50. Leterme P (2002) Recommendations by health organizations for pulse consumption. Br J Nutr 88(Suppl 3):S239-S242 